thalmia it is not a question of removing the exciting eye only. We should remove not only one-half or three-fourths or seven-eighths of the poison or source of poisoning, but all of it. Having a case of uveitis we should search all the possible locations for focal infections and not be content with the removal of the focus which is located in the exciting eye.

\section{CONCLUSIONS.}

Sympathetic ophthalmia is an anaphylactic inflammation of the sympathizing eye.

Elschnig is right in so considering it, altho I cannot believe that such anaphylaxis is always caused by proteins originating in the digestive tract.

A focal infection caused by an invader similar to that implanted in the exciting eye furnishes the larger dosage required to determine anaphylaxis. (The sensitizing dose being always less than the determining dose.)

Besides the size of the dosage other factors enter into the process, such as predilection, virulence, and affinity of the bacteria.
In every endogenous uveitis the proteins of the septic emboli have already been subjected to, and perhaps modified by, the nonspecific defenses of the blood, as well as the specific defenses of the focal area, from which they may have escaped. This suggests a possible reason why the processes of local immunization are ordinarily operative, and that immunity not sensitization is the usual outcome in loco.

With the implantation, llowever, of bacteria from without which have not been so subjected or modified, having certain affinities, the establishment of a local defense creates predilection for this same tissue and the second eye is thus sensitized rather than immunized.

The focal infection now supplies the increased dosage required to bring about an anaphylactic reaction and after the time necessary to sensitize has elapsed the reaction occurs.

This hypothesis gives us a working guide as to what we may do for the patient, namely, give him the most minute search for focal infections.

\title{
VISUAL DEFECTS OF THE WEST POINT CADETS.
}

\author{
Capre. Kennetil A. Phelps, M.C., U. S. A.
}

MINNEAPOLIS, MINNESOTA.

This is a study based on statistics of the past six classes of the Military Academy, presented in tabular form.

The West Pointer is trained to be as nearly physically perfect as possible. He is carefully selected, physically, before he is admitted; and almost the only defect he is allowed to have on entrance is one of vision. The visual requirements are as follows:

For the Hyperopic: Vision must be $20 / 30$ correctible to $20 / 20$.

For the Myopic: Vision must be $20 / 40$ correctible to $20 / 20$.

For the Astigmatic: Vision must be $20 / 30$ correctible to $20 / 20$.

In all cases there must be no disease of the fundus.

This, from the start, means that more myopes are admitted than hyperopes (statistics show six to one). Myopia develops or becomes known during the course of the cadet more often than hyperopia (curiously enough the statistics show 6 to 1 here also). Hence the refraction problem is one dealing with myopia almost entirely, and probably, for this reason, the graduation requirements are $20 / 100$ in each eye correctible to $20 / 20$.

As the classes have increased in number it is interesting to note that the percentage of defects in vision, both at admission $10 \%$ and graduation $20 \%$, have remained practically fixed. This shows that about the same relative number develop trouble in the cadet corps as were admitted with it. 
The cadets' work during the summer is outdoor work, requiring good distant vision for firing on the range; and on practice marches for reading signals and, with the field glass, to pick up silhouette and moving targets. Without good vision he misses seeing the "enemy" and is unable to direct the fire of his men, either as to direction or range. The man in the ranks needs vision enough to make out rough landmarks. He does not need to see the enemy, as his target is designated for him by his officer.

In winter the cadet must study long hours, often over fine work such as higher mathematics and mechanical drawing, which requires more accurate vision than reading only. He recites daily and his standing depends on daily averages, so he must work.

These long hours of work produce a spasm of the ciliary muscle which might be mistaken for a pure myopia. In the Spring the vision is often $20 / 70$ or less and after the Summer's rest from near work the vision comes up to $20 / 30$ or $20 / 40$. These cases are so frequent that it is not rare to hear graduates of West Point talk about the "pecular eye condition of the cadets at the Point." This condition is a permanent state of excessive tension of the ciliary muscle; and mainly affects myopic eyes, which, by it, are made to appear more myopic than they really are, and is distinct "from the continuous tension of the ciliary muscles in hypermetropes when overcoming their hypermetropia so as to see clistinctly." (Fuchs p. 910.) We found no fundus lesions, no field changes and no tension changes in any of thrse cases, but all were in myopes, and in some there was an apparent decrease in the range of accommodation.

Owing to the need of each caclet being able to work each day, it is very hard for them to give up time to be refracted under atropin or to have atropin used as treatment. We adopted the plan of re- fracting every man with a known defect during the summer, and should one develop trouble later we had saved him the loss of time due to a cycloplegic.

At each graduation time we found $20 \%$ of the class with visual defects. One-fourth of these read 20/70 in one eye and 20/100 in the other, and another fourth could not read that much. All these men were accepted into the army as officers, and about half of them started in the Academy with defects of vision which progressed each year. Our figures show that $50 \%$ of the men who were admitted with vision below normal had progressively lower vision at each examination.

When a man reported for examination for admission and we found a visual defect, we felt that his chance of the defect progressing were "fifty-fifty," and almost no chance at all for improvement. One out of every ten men will develop trouble before he graduates.

In 1917 we found that the system of lights was very poor. Most of the men sat in a glare so the wearing of eye shades was almost universal, and at the same time they were working in shadows. Each man sat at his table with a light behind him, so arranged that it shone into the eyes of his room-mate. We had a better system put in and were hoping to have less trouble, when the size of the cadet corps was increased so that often four men were put into a room intended for two. This made it impassible to tell how much the improper lights had to do with the development and the progress of visual defects.

Much of this condition could be eliminated by a strict adherence to the entrance requirements which we believe should be $20 / 20$ in each eye. Certainly no case not meeting the requirements should be placed on probation, for there is very little chance for improvement taking place to meet later requirements. 
Summary of Visual Defects in Classes (1916-1921) Table I

Total De- \% De- Abnormal on admission- Normal on admission

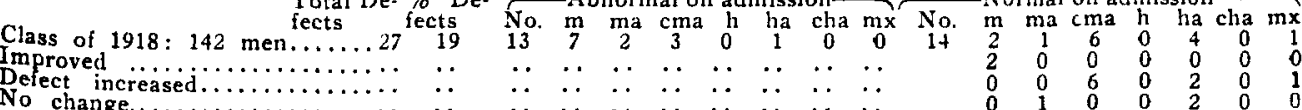

No change.....................

Class of 1919: 137 men.......30

Improved

.

Defect increased

No change. .................

Class of 1920: 237 men......34

Improved $\ldots \ldots \ldots \ldots \ldots \ldots \ldots$

Defect increased................

Class of $1921: 313$ men....... 6

Improved $\ldots \ldots \ldots \ldots \ldots \ldots \ldots \ldots$

Defect increased.

No change...................

$\begin{array}{rrrrrrrrr}21.9 & 16 & 10 & 0 & 5 & 0 & 0 & 1 & 0 \\ \therefore & 0 & 0 & 0 & 0 & 0 & 0 & 0 & 0\end{array}$

$\begin{array}{lllllllll} & 0 & 5 & 0 & 4 & 0 & 0 & 1 & 0\end{array}$

$\begin{array}{rrrrrrrrr}14.3 & 18 & 13 & 1 & 0 & 0 & 1 & 3 & 0 \\ \because . & \ldots & 1 & 0 & 0 & 0 & 0 & 1 & 0 \\ \because & \therefore & 9 & 0 & 0 & 0 & 0 & 0 & 0\end{array}$

$\begin{array}{lllllllll}\therefore & \therefore & 9 & 0 & 0 & 0 & 0 & 0 & 0 \\ & \therefore & 4 & 1 & 0 & 0 & 1 & 2 & 0\end{array}$

Class of 1917 :

2 years before graduation....11

Class of 1916 :

126 men. 1 year before

Eraduation ................18

$\begin{array}{lllllllll}14.8 & 14 & 8 & 0 & 1 & 0 & 2 & 3 & 0 \\ \because & \cdots & 0 & 0 & 0 & 0 & 0 & 0 & 0 \\ \cdots & \cdots & 8 & 0 & 1 & 0 & 2 & 3 & 0\end{array}$

$\begin{array}{lllllllll}\cdots & \cdots & 8 & 0 & 1 & 0 & 2 & 3 & 0\end{array}$

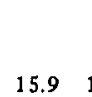

$6 \quad 4$

0

$\begin{array}{lll}0 & 0 & 0 \\ 0 & 0 & 0\end{array}$

147

$\begin{array}{lllllll}3 & 0 & 3 & 0 & 1 & 1 & 1\end{array}$

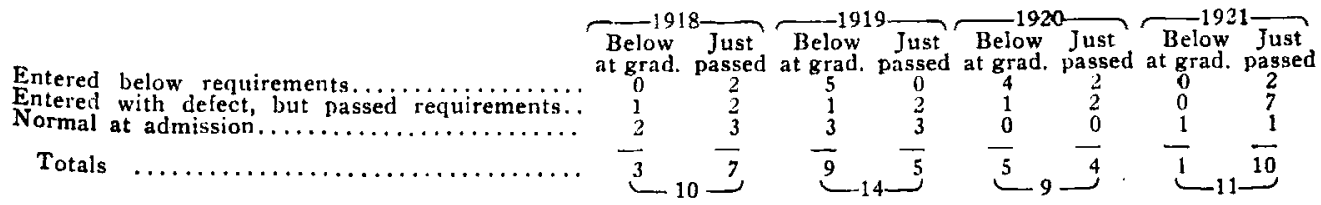

KEY TO TABLE I.

M-Myopia. Ma-Myopic Astigmatism. Cma-Compd. Myopic Astigmatism. H-Hyperopia. Ha-Hyperopic Astigmatism. Cha-Compd. Hyperopic Astigmatism. Mx-Mixed Astigmatism.

\section{CYCLODIALYSIS.}

\section{H. S. Gradie, M.D., F.A.C.S., \\ CHICAGO, JLLINOIS.}

The history and method of performing this operation, the manner in which it proves effective, the class of cases to which it is suited and the results obtained by it, are here discussed with six abstracts of illustrative cases, and a bibliography. Read before the American Academy of Ophthalmology and Oto-Laryngology, October 18, 1919.

History. In 1905 at the Heidelberg Ophthalmological Congress, Heine' first described an operation which he had performed twenty-six times for the relief of increased intraocular tension. He termed the procedure "Cyclodialysis," a name which has remained. The technic was set forth in detail as were the cases upon which it was tried, followed by a discussion of the modus operandi resulting in a balance of intraocular tension. This latter point will be set forth at length in the subsequent pages. The operation found favor immediately in the Continental Clinics, where it was tried extensively on ill forms of increased tension. But in this country only a few operators attempted the procedure.
Technic. The following are the steps of the operation:-

a.) Usual aseptic precautions with instruments, conjunctival sac, etc.

b.) Curvilinear incision of the conjunctiva, 8 millimeters long and 8-10 millimeters above the limbus.

c.) Free undermining of the conjunctiva toward the limbus.

d.) Tangential incision thru the sclera, 6 millimeters long and 6-8 millimeters above the limbus.

e.) Introduction of the cyclodialysis spatula thru the incision, hugging the inner surface of the sclera, while a forcible rocking motion thrusts the tip of the spatula into the anterior chamber.

f.) Free sweeping motion of the spatula to the right and left, forcibly 